\title{
19 ANOS DE CIÊNCIAS MÉDICAS E BIOLÓGICAS
}

ISSN 1677-5090 e 2236-5222

\section{2 a 2020 - Revista de Ciências Médicas e Biológicas}

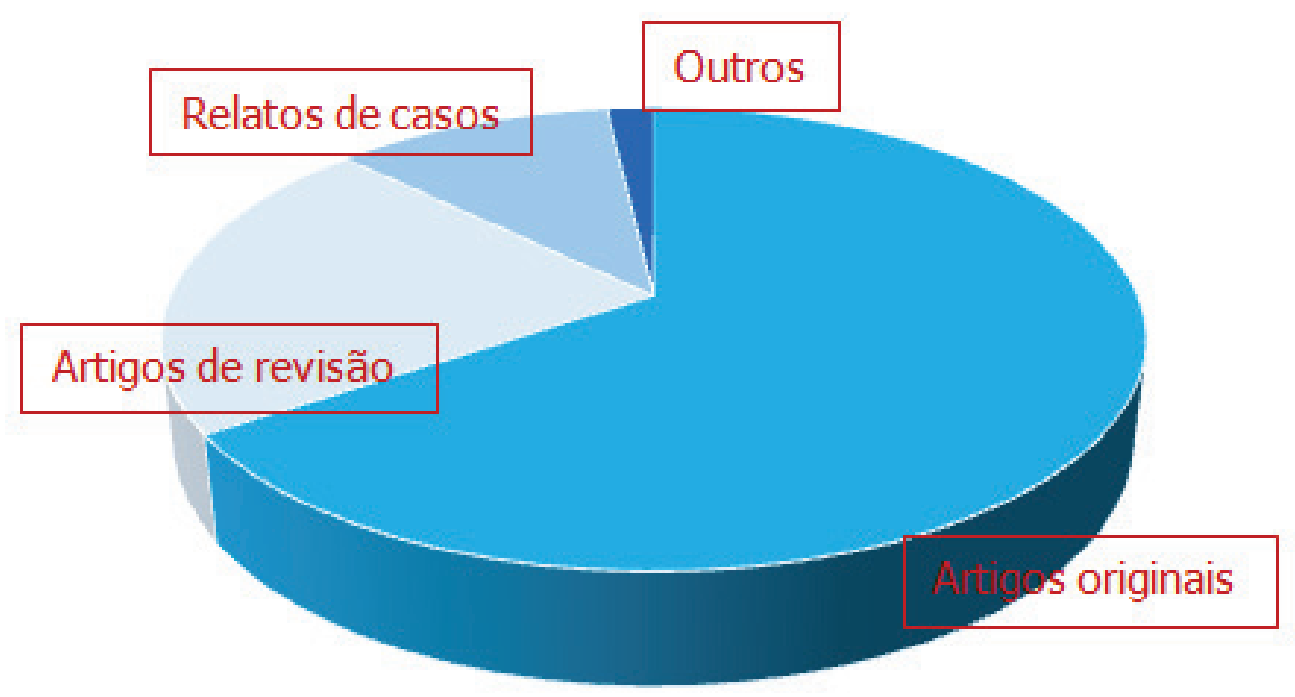

A análise da figura ilustrativa dos dezenove anos da Revista de Ciências Médicas e Biológicas revela através dos 55 fascículos publicados a divulgação de 652 artigos originais, 215 artigos de revisão, 109 relatos de casos clínicos e 18 produções outras, entre as quais, textos que tratam de atualizações e conferências, além de 6 fascículos especiais contendo os anais de eventos científicos produzidos pelo Programa de Pós-graduação em Imunologia e pelo Programa de pós-graduação Processos interativos dos Órgãos e Sistemas da Universidade Federal da Bahia. A essa expressiva divulgação de produção acadêmica da comunidade científica são acrescidos 55 editoriais que têm contado com a colaboração de docentes e pesquisadores.

Os suplementos especiais divulgam os importantes eventos científicos, tais como:

"I Simpósio Interdisciplinar de Órgãos e Sistemas. 2011".

"Anais da XVI EXPOPPGIM. 2016".

"Anais da XVII EXPOPPGIM 2017".

"Anais da XVIII EXPOPPGIM 2018".

"V Simpósio Internacional de Neuroquímica e Fisiopatologia da Célula Glial 2019".

"I Simpósio Norte-Nordeste em Imunologia 2020".

“I Simpósio Norte-Nordeste em Imunologia 2020".

Esses eventos expressam a relevância das atividades acadêmicas que congregaram através de Programas de Pós-graduação da UFBA credenciados pela CAPES, a participação de importantes pesquisadores que discutem temas sobre os mais diversos aspectos envolvendo as ciências básicas e aplicadas, tendo como referenciais a homeostasia e os distúrbios da homeostasia. 
Um relevante indicador de qualidade deste Periódico ora em destaque e que vem sendo consolidado a cada fascículo, é o aumento da demanda pela publicação de artigos assinados por professores e/ou pesquisadores, mestrandos, doutorandos, pós-doutorandos e estudantes bolsistas de iniciação científica, vinculados aos mais diversos laboratórios e órgãos de Instituições de Ensino Superior e Centros de Pesquisa nacionais e internacionais. Merece destaque o rigoroso atendimento dado à periodicidade, o cuidado dispensado aos textos registrados em português, a especial atenção dada aos textos em língua estrangeira e aos critérios de normalização, assim como o cuidado especial dispensado à editoração eletrônica e à revisão das submissões de artigos realizada por pares. Apesar da Editoria da Revista disponibilizar a possibilidade de publicação através dos ISSN 1677-5090 e 2236-5222, constata-se a crescente a preferência dos autores pela versão on line.

Criada em 2002, a Revista de Ciências Médicas e Biológicas acha-se indexada nas bases de dados LILACS, LATINDEX, BBO, BVS, SIBRADID, Academic Google e Portal de Periódicos da CAPES, sendo que neste momento encontra-se em avaliação a possibilidade de registro em outros importantes indexadores científicos. Marcadamente ética, esta Revista não veicula propagandas, no momento não possui financiamento de agências de fomento, e conta, apenas, com o apoio institucional da CAPES e da Universidade Federal da Bahia

Espera-se, dessa forma, continuar merecendo o crédito e o entusiasmo da comunidade científica que confia a divulgação de parcela relevante de sua produção científica à Revista de Ciências Médicas e Biológicas.

Roberto Paulo Correia de Araújo

Professor Permanente do Programa de Pós-graduação Processos Interativos dos Órgãos e Sistemas - UFBA

Diretor do Instituto de Ciências da Saúde - UFBA

Editor Científico da Revista de Ciências Médicas e Biológicas 